\title{
Heterochrony, cannibalism, and the evolution of viviparity in Salamandra salamandra
}

\author{
David Buckley, ${ }^{a, b}, *$ Marina Alcobendas, ${ }^{a}$ Mario García-París, a and Marvalee H. Wake ${ }^{b}$ \\ ${ }^{a}$ Museo Nacional de Ciencias Naturales, José Gutiérrez Abascal 2, 28006 Madrid, Spain \\ ${ }^{b}$ Department of Integrative Biology and Museum of Vertebrate Zoology, 3060 VLSB, University of California, Berkeley, \\ CA 94720-3140, USA \\ *Author for correspondence (email: dbuckley@berkeley.edu)
}

\begin{abstract}
SUMMARY The way in which novelties that lead to macroevolutionary events originate is a major question in evolutionary biology, and one that can be addressed using the fire salamander (Salamandra salamandra) as a model system. It is exceptional among amphibians in displaying intraspecific diversity of reproductive strategies. In $S$. salamandra, two distinct modes of reproduction co-occur: the common mode, ovoviviparity (females giving birth to many small larvae), and a phylogenetically derived reproductive strategy, viviparity (females producing only a few large, fully metamorphosed juveniles, which are nourished maternally). We examine the relationship between heterochronic modifications of the ontogeny and the evolution of the new reproductive mode in the fire salamander. The in vitro development of embryos of
\end{abstract}

ovoviviparous and viviparous salamanders from fertilization to metamorphosis is compared, highlighting the key events that distinguish the two modes of reproduction. We identify the heterochronic events that, together with the intrauterine cannibalistic behavior, characterize the derived viviparous reproductive strategy. The ways in which evolutionary novelties can arise by modification of developmental programs can be studied in $S$. salamandra. Moreover, the variation in reproductive modes and the associated variation of sequences of development occur in neighboring, conspecific populations. Thus, $S$. salamandra is a unique biological system in which evolutionary developmental research questions can be addressed at the level of populations.

\section{INTRODUCTION}

Amphibians possess complex life cycles; in many, the cycle consists of free-living aquatic larvae that metamorphose into terrestrial adults (Duellman and Trueb 1986). This biphasic life cycle involves two, morphologically distinct developmental stages, each of which occurs in a different environment - that is, larvae in water and terrestrial adults on land. The evolutionary potential of amphibians is tied to the biphasic life cycle and the distinct selective pressures that are brought to bear on the individual in the different ecological contexts (Wake and Roth 1989; Hanken 1999).

The presumably ancestral biphasic life cycle has been modified repeatedly in the three orders of extant amphibians. Modifications range from species with perennial larvae (e.g., permanent paedomorphic salamanders, summarized by Duellman and Trueb 1986; Wiens et al. 2005; Bonett and Chippindale 2006; Safi et al. 2006) to direct developers, in which the free-living larval stage is absent and adult structures form directly from the embryos (e.g., Eleutherodactylus frogs, many salamanders of the family Plethodontidae, and some caecilians of the family Caeciliidae; Wake 1982, 1989). Many variants are found within this broad reproductive continuum, including the repeated and independent transitions from oviparity to viviparity in the three amphibian orders (e.g., Wake 1982, 1993, 2004) and the evolution of environmentally driven reproductive strategies (e.g., facultative paedomorphic urodeles, Whiteman 1994; Ryan and Semlitsch 2003; Denoël et al. 2005), as well as the evolution of elaborate mating systems and parental care strategies (e.g., Duellman and Trueb 1986; Beck 1998; Duellman 2003; Lehtinen and Nussbaum 2003; Nussbaum 2003; Haddad and Prado 2005; Summers et al. 2006).

Variations in life-history traits of amphibians often relate to modifications of the developmental sequences (Hanken 1992; Bruce 2003). Ontogenetic modifications may be key events in the evolution of larval and adult structures (e.g., Alberch 1989). Many such modification are heterochronic - that is, they involve shifts in the relative timing of developmental events in a descendant organism compared to the timing of the same events in an ancestor (Gould 1977; Alberch et al. 1979; McKinney and McNamara 1991; Zelditch 2001; McNamara and McKinney 2005). As several authors have pointed out (e.g., Fink 1982; Alberch 1995; Smith 2002), in practice almost all studies of heterochrony involve a comparative analysis among phylogenetically 
related taxa, because information on the timing of developmental events in ancestors is not available. Heterochrony is considered to be a linking concept between development and evolution and, as such, it is a paradigm in the study of morphological evolution (Alberch and Blanco 1996; Poe and Wake 2004). The importance of heterochronic processes in amphibian evolution has been discussed extensively (e.g., Wake and Roth 1989; Hanken 1992, 1999 and references therein). These kinds of ontogenetic modifications are thought to underlie the evolution of structures or body parts (e.g., limb morphology or pigmentation: Blanco and Alberch 1992; Parichy 2001), the evolution of some modes of reproduction (e.g., facultative paedomorphic urodeles: Gould 1977; Ryan and Semlitsch 1998; Denoël and Joly 2000; Denoël et al. 2005), and the evolution of complex life cycles (Hanken 1992, 1999; Bruce 2003).

\section{SALAMANDRA SALAMANDRA: THE BIOLOGICAL MODEL}

Intraspecific diversity in reproductive strategies is rare among vertebrates. Examples of polymorphisms that involve cooccurrence of oviparity and ovoviviparity, or even viviparity with various degrees of structural modifications, have been documented for several lizard species (e.g., Shine 1985; Mink and Sites 1996; Andrews 1997; Heulin et al. 1997; Smith and Shine 1997; Qualls and Shine 1998). Facultative paedomorphosis in some species of urodeles is another example, although in these cases, reproductive bimodality in populations is environmentally induced (Whiteman 1994; Ryan and Semlitsch 1998; Denoël and Joly 2000; Denoël et al. 2005).

Fire salamanders $(S$. salamandra) represent a striking example of biological polymorphism within a species. Morphological diversification in $S$. salamandra includes variation in size (13-22 cm in snout-vent length for adult females), body proportions, head shape, and coloration. In addition, the duration of the larval period varies, extending from a few months to more than 1 year (Joly 1986; Salvador and GarcíaParís 2001). There is also diversity in reproductive strategies. Female $S$. salamandra may be ovoviviparous, in which case 30-60 larvae are produced at some stage before metamorphosis is complete, with yolk being their only source of nutrition (larviparity sensu Greven 2003). Alternately, female fire salamanders can be viviparous. In this phylogenetically derived reproductive mode (Veith et al. 1998; García-París et al. 2003; Weisrock et al. 2006), 1-15 fully metamorphosed juveniles are born; in addition to yolk, maternal nutrition is provided (pueriparity sensu Greven 2003; Blackburn 1994; Wake 1989, 1992, 2002, 2004). Viviparity in S. salamandra is characterized by the early hatching of the embryos within the maternal oviducts and by the phenomena of oophagy and adelphophagy - that is, intra-oviductal ingestion of eggs or larvae, respectively (Wourms 1981; Joly 1986; Dopazo and Alberch 1994; Greven 1998). Furthermore, the developmental rate of viviparous embryos is accelerated (Dopazo and Alberch 1994; Dopazo and Korenblum 2000).

Viviparity occurs in populations of the northern Iberian subspecies S. salamandra bernardezi and S. s. fastuosa. Viviparous populations are not geographically isolated, but they occur within the continuous range of distribution of the species in the Iberian Peninsula. Thus, viviparous populations are surrounded by ovoviviparous populations of salamanders (Joly 1986; Thiesmeier and Haker 1990; Dopazo and Alberch 1994; Alcobendas et al. 1996). A paleogeographic scenario and a population model based on the phylogenetic and phylogeographic analysis of mitochondrial and nuclear DNA markers was proposed to explain the evolutionary history of $S$. salamandra in the Iberian Peninsula (García-París et al. 2003). Intraspecific lineage divergence within $S$. salamandra is a consequence of vicariant processes in the late Pliocene. Viviparity likely arose in the isolated populations on the northern slopes of the Cantabrian Mountains (northern Iberian Peninsula). Posterior range shifts as a result of climate oscillations facilitated secondary contact among isolated lineages. Large demographic expansions, possibly favored by a selective advantage of the newly evolved reproductive mode, might have led to the admixture and homogenization of previously differentiated genomes. These genomic changes might have resulted in the spread of viviparity, together with other nuclear-encoded traits (e.g., striped coloration) to the current distribution of the derived reproductive mode in the northern Iberian Peninsula (García-París et al. 2003).

The preliminary data on viviparity in $S$. salamandra and the importance of developmental heterochronic processes in the evolution of reproductive strategies and life-history traits in urodeles suggest that the evolution of viviparity in $S$. salamandra might be related to ontogenetic modifications (Dopazo and Alberch 1994). Herein, the ontogenies of viviparous and ovoviviparous $S$. salamandra are compared. We reared in vitro embryos of $S$. salamandra from fertilization to metamorphosis and identified the key events that distinguish reproductive modes. Heterochronic changes are associated with the occurrence of viviparity and ovoviviparity within a single species. Such events can lead to new adaptive pathways, and are examples of small developmental changes that produce evolutionary novelties in a lineage - that is, the process through which microevolutionary events produce macroevolutionary patterns.

\section{COMPARING DEVELOPMENTAL SEQUENCES}

We studied the development of embryos from fertilization to metamorphosis in eight viviparous $S$. Salamandra from Oviedo (Asturias, northern Spain, $43^{\circ} 21^{\prime} 5^{\prime \prime} \mathrm{N} 06^{\circ} 09^{\prime} 02^{\prime \prime} \mathrm{W}$ ); this 
is the type locality of $S$. $s$. bernardezi and the first population described as obligatorily viviparous in the species (Thiesmeier and Haker 1990). In addition, we studied nine ovoviviparous S. s. bejarae from Mijares, (Ávila, central Spain $40^{\circ} 20^{\prime} 01^{\prime \prime} \mathrm{N}$ $05^{\circ} 11^{\prime} 21^{\prime \prime} \mathrm{W}$; Table 1). Females were captured after the mating season (March-May); they were kept in laboratory at 14 $17^{\circ} \mathrm{C}$ in $12 \mathrm{~h}$ light: $12 \mathrm{~h}$ dark cycles, and fed earthworms twice a week. Mating and fertilization of ova are decoupled in the fire salamander. Females store the sperm in a spermatheca until they complete the vitellogenic cycle and the eggs are ready to be fertilized (e.g., Joly 1986; Greven and Guex 1994). Fertilization occurs after ovulation, which can be assessed by a patent change in female body shape. Once ovulation was confirmed, we sacrificed one viviparous and one ovoviviparous female with an overdose of anesthesia (Benzocaine). The ova of females in early pregnancy were removed and cultured in a $10 \%$ Holtfreter solution (Armstrong et al. 1989) at $17^{\circ} \mathrm{C}$ in $9 \mathrm{~cm}$ diameter, $3.5 \mathrm{~cm}$ high plastic culture dishes. All the eggs contained in one uterus were cultured together in one culture dish (two dishes per female, one per uterus). The other females were sacrificed sequentially, every $3-4$ to $10-15$ days. The experimental design permits us to obtain a consistent and reliable sample of overlapping developmental series of embryos from fertilization to metamorphosis from different females. We followed and photographed the embryos with a Nikon FX-35WA camera coupled to a Nikon SMZ-10 stereomicroscope. We used the development stages of fore- and hind limbs, as well as a temporal axis, as the reference points to compare the developmental events of both ontogenetic sequences. Legal collecting permits, issued by the pertinent Spanish Regional Environmental Agencies, supported the collections. The University of California, Berkeley, Animal Care and Use Committee approved the experimental procedure described.

\section{ONTOGENETIC SEQUENCES IN OVOVIVIPAROUS AND VIVIPAROUS FIRE SALAMANDERS}

We obtained fertilized eggs, embryos, or larvae from 14 of the 17 females studied; one viviparous and two ovoviviparous females did not reproduce. Samples analyzed are summarized in Table 1. A staging table for the regular developmental sequence in $S$. salamandra (ovoviviparous) will be given elsewhere (Buckley et al. in preparation). Here, we highlight the primary differences between the development of viviparous and ovoviviparous embryos.

Fertilization of eggs in $S$. salamandra is associated with ovulation, which occurs during the first week of July in both viviparous and ovoviviparous females from the two populations studied. This pattern is consistent with the reproductive cycles described for populations occurring in similar habitats, although reproductive patterns may greatly vary in different
Table 1. Samples analyzed

\begin{tabular}{lcll}
\hline Female & Day/month & \multicolumn{1}{c}{ Right oviduct } & Left oviduct \\
\hline Vivip-1 & $15 / 06$ & $53 \mathrm{O}$ & $50 \mathrm{O}$ \\
Vivip-2 & $14 / 07$ & $4 \mathrm{~L}$ & $4 \mathrm{~L}$ \\
Vivip-3 & $18 / 07$ & $8 \mathrm{E}+33 \mathrm{O}$ & $3 \mathrm{E}+41 \mathrm{O}$ \\
Vivip-4 & $18 / 07$ & $4 \mathrm{E}+16 \mathrm{O}$ & $3 \mathrm{E}+27 \mathrm{O}$ \\
Vivip-5 & $18 / 07$ & $12 \mathrm{~L}$ & $10 \mathrm{~L}+1 \mathrm{O}$ \\
Vivip-6 & $31 / 07$ & $6 \mathrm{~L}+30 \mathrm{O}$ & $9 \mathrm{~L}+31 \mathrm{O}$ \\
Vivip-7 & $31 / 07$ & No ovulation & No ovulation \\
Vivip-8 & $19 / 08$ & $35 \mathrm{O}$ & $3 \mathrm{~L}$ \\
Ovovovip-1 & $06 / 05$ & No ovulation & No ovulation \\
Ovovovip-2 & $24 / 06$ & No ovulation & No ovulation \\
Ovovovip-3 & $12 / 07$ & $16 \mathrm{O}$ & $26 \mathrm{O}$ \\
Ovovovip-4 & $13 / 07$ & $25 \mathrm{O}$ & $32 \mathrm{O}$ \\
Ovovovip-5 & $18 / 07$ & $31 \mathrm{O}$ & $29 \mathrm{O}$ \\
Ovovovip-6 & $18 / 07$ & $22 \mathrm{E}$ & $19 \mathrm{E}$ \\
Ovovovip-7 & $31 / 07$ & $24 \mathrm{E}+1 \mathrm{O}$ & $23 \mathrm{E}+1 \mathrm{O}$ \\
Ovovovip-8 & $12 / 11$ & $13 \mathrm{~L}$ & $21 \mathrm{~L}+1 \mathrm{H}$ \\
Ovovovip-9 & $12 / 12$ & 29 larvae delivered & \\
\hline
\end{tabular}

Vivip- and Ovovivip-, viviparous and ovoviviparous females from Oviedo and Mijares, respectively; day/month, date when females were dissected; E, embryos; O, ova (either fertilized or arrested); L, larvae. In viviparous females we designate as "larvae" individuals that have already hatched and are actively feeding within the maternal oviducts. In ovoviviparous females, "larvae" are the individuals that have attained the larval morphology and are ready to initiate the free-living aquatic stage after delivery.

environmental conditions (Joly 1986; Greven and Guex 1994; Joly et al. 1994; Greven 2003; D. Buckley personal observations). Ovoviviparous females ovulate between 20 and 60 eggs; upon fertilization, nearly all undergo intrauterine development to hatching. Hatching in ovoviviparous S. salamandra typically occurs during, or just before, the release of larvae into water. In our laboratory conditions, ovoviviparous females gave birth to larvae after 80-90 days of intrauterine development. The newly released larvae are large $(20-35 \mathrm{~mm}$ total length), with fully developed gills, limbs, and eyes, and conspicuous ventral and dorsal tail fins; they feed immediately. Development to this stage depends solely on yolk provision (lecithotrophy). The length of the larval period varies depending on environmental conditions (Alcobendas et al. 2004). Viviparous females also ovulate numerous eggs, but they develop through metamorphosis entirely within the maternal genital tract, and only a few (1-15) fully metamorphosed terrestrial juveniles are born after 80-90 days of gestation.

The following differences were noted in in vitro development of viviparous and ovoviviparous embryos (Figs. 1 and 2).

(1) Development is arrested in many eggs (up to $50 \%$ in some cases) in all the viviparous females analyzed (Fig. 1a), whereas in ovoviviparous salamanders, no developmental arrestment occurs (Fig. 1b). In each arrested egg, a yolk 

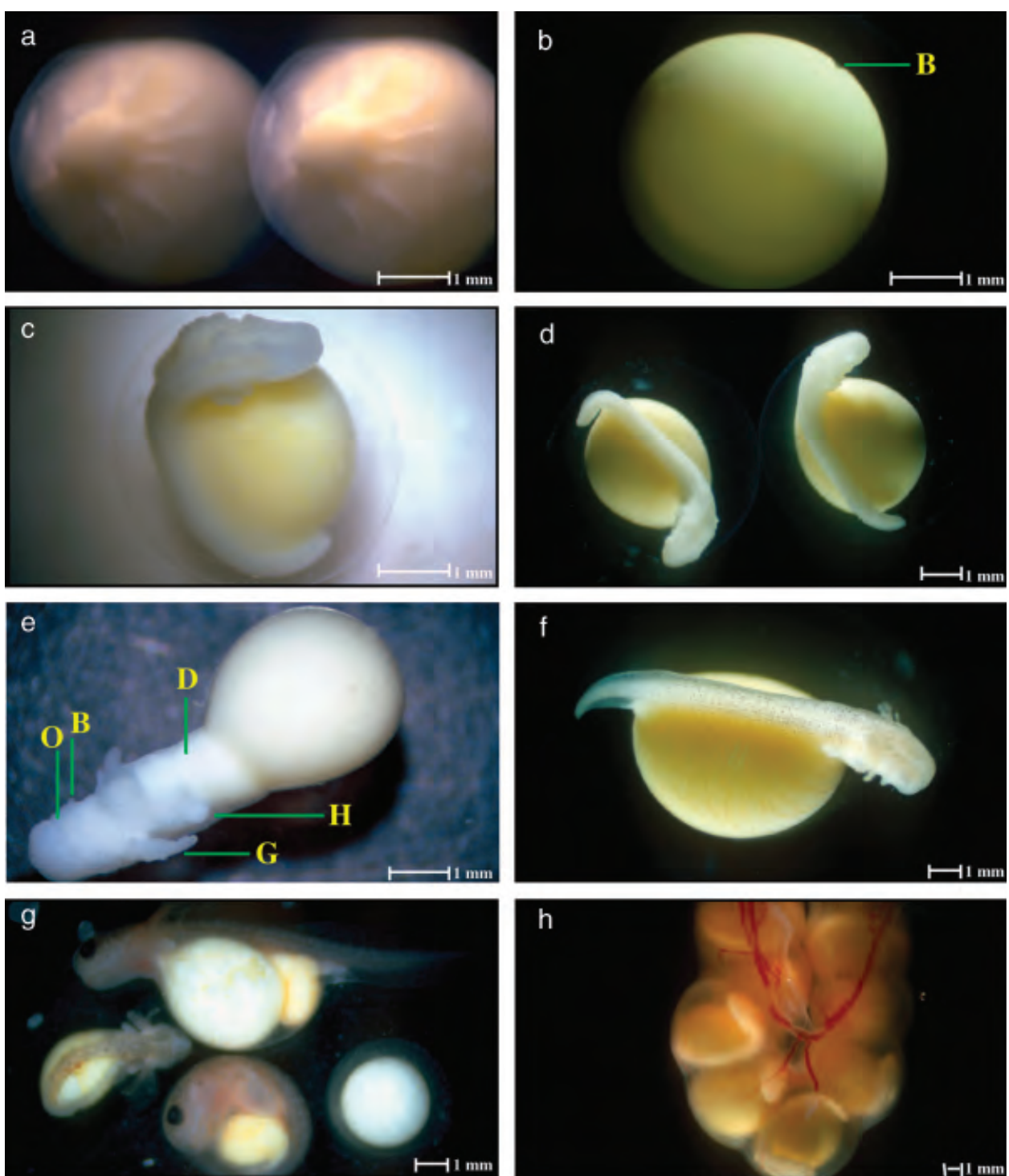

VIVIPAROUS

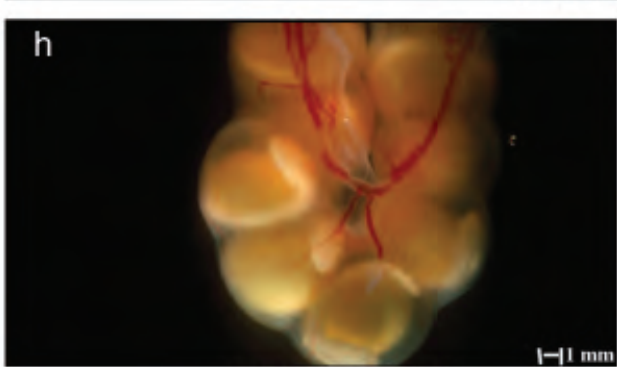

OVOVIVIPAROUS

Fig. 1. Comparable developmental stages of viviparous and ovoviviparous salamander embryos. Comparable stages corresponding to the development of the fore- and hindlimbs are contrasted, highlighting the main differences found during the development of viviparous (left column) and ovoviviparous (right column) salamanders (see the text for a more detailed description of the developmental stages). (a, b) Viviparous, (a) and ovoviviparous, (b) eggs at gastrulation. The presence of numerous abortive eggs is the rule in viviparous females. Some of them present a yolk plug that obliterates the blastopore (a). Abortive eggs are barely found in ovoviviparous females (b), the majority of the eggs following a normal gastrulation process (B: blastopore). (c, d) Viviparous and ovoviviparous embryos present the same degree of differentiation of the cephalic structures (although the head and the tail are already separated from the yolk mass in ovoviviparous embryos but not in viviparous ones). Viviparous embryos attain such a state in 3-4 days, while ovoviviparous embryos take around 9 days. The development of viviparous embryos is thus accelerated during the lecithotrophic phase of the ontogeny. (e, f) When the forelimbs are at the bud stage $(\mathrm{H})$, viviparous and ovoviviparous embryos are morphologically very different. Yolk has been quickly consumed by the viviparous embryos that, furthermore, have already hatched. Hatching in ovoviviparous individuals occurs much later, when they are laid in water to initiate the larval aquatic phase. The development of oral groove $(\mathrm{O})$, balancers $(\mathrm{B})$, and gills $(\mathrm{G})$ is similar in
ovoviviparous and viviparous embryos. The latter, however, present an early-differentiated pharyngeal region and digestive tract (D). (g, h) Viviparous embryos are normally found at very different developmental stages within the oviducts (g). This heterogeneity in developmental stages is never found in ovoviviparous females, in which the eggs are all fertilized and develop synchronously (h). This difference has been consistently found in all the viviparous and ovoviviparous salamanders studied.

plug obliterated the blastopore, a phenomenon that may reflect a dysfunctionality of the neurulation process (cf. arrested developmental syndrome in newts; Sessions et al. 1988).

(2) The degree of differentiation of the cephalic structures and gills is the same in ovoviviparous and viviparous embryos. However, the embryos are disposed differently on the yolk masses (Fig. 1, c and d); whereas the cephalic and caudal regions are clearly elevated in the ovoviviparous embryos, the viviparous ones are tightly curled around the yolk. The latter attain such a degree of dif- ferentiation in 3 or 4 days, whereas the ovoviviparous embryos require 9 days.

(3) After 8 or 9 days of development, the cephalic and pharingeal regions of the viviparous embryos are enlarged and advanced in development relative to those of ovoviviparous embryos (Fig. 1e). The cephalic and pharyngeal regions are separated from the yolk masses, which are now located in the posterior part of the body. The embryos have three pairs of unramified gills $(\mathrm{G})$, a shallow oral groove $(\mathrm{O})$, well-developed optic vesicles, two rudimentary balancers (B), and incipient forelimb buds $(\mathrm{H})$. 

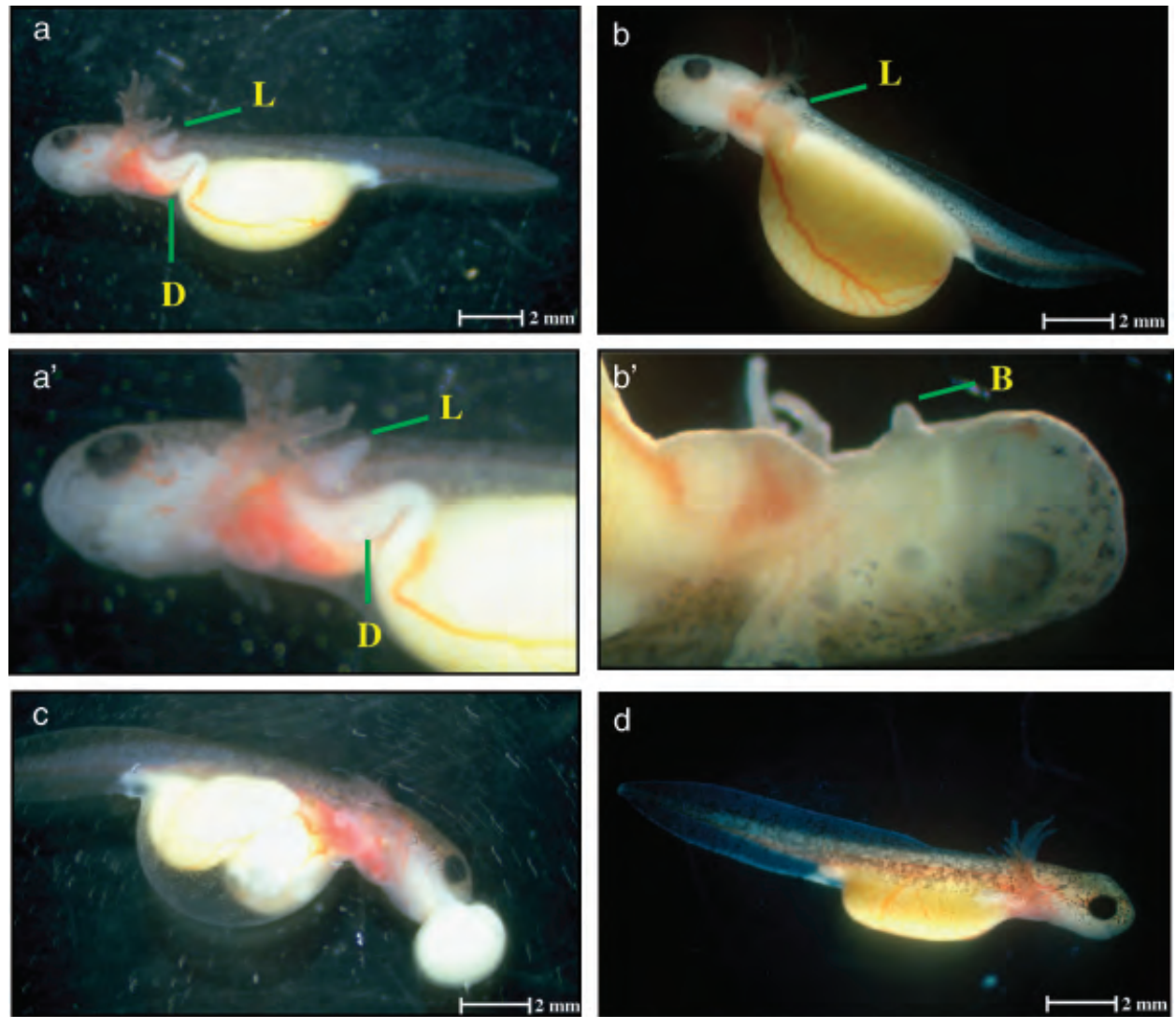

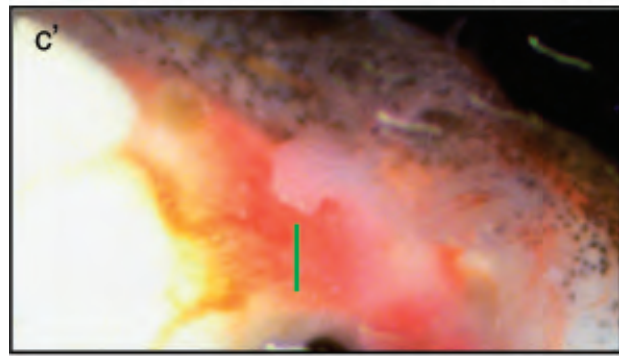

VIVIPAROUS

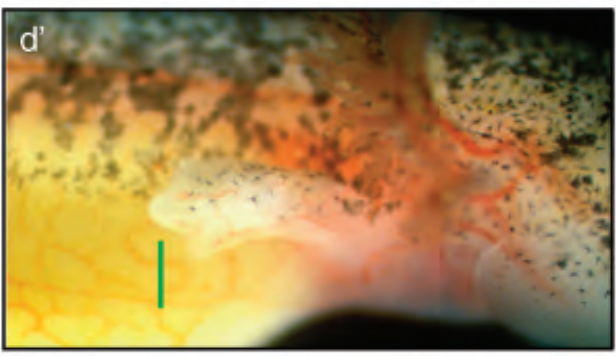

OVOVIVIPAROUS

Fig. 2. As in Fig. 1, the main differences found during the development of viviparous (left column) and ovoviviparous (right column) salamanders are highlighted. $(\mathrm{a}, \mathrm{b})$ At this developmental stage (forelimbs enlarged as conical structures [L]), the mouth of the viviparous embryos opens. Balancers have been resorbed and the foregut (D) is already differentiated ( $a$ and $a^{\prime}$ ). None of these features occur in ovoviviparous embryos $\left(\mathrm{b}\right.$ and $\left.\mathrm{b}^{\prime}\right)$. The mouth is still closed and the balancers $(\mathrm{B})$ are present $\left(\mathrm{b}^{\prime}\right)$. The yolk mass is still very prominent and is located where the digestive tract will differentiate later in development. (c, d) Once their mouths are opened, viviparous embryos feed actively on abortive eggs and sibs. Transition from the lecithotrophic phase to active feeding occurs very early during the development of viviparous embryos (forelimbs as conical or palm structures $\left[\mathrm{a}^{\prime}\right.$ and $\left.\mathrm{c}^{\prime}\right]$ ). The ingested nutrients fill the part of the digestive tract that differentiated precociously. Some examples of this intrauterine cannibalistic behavior are shown in Fig. 3. Intrauterine cannibalism never occurs in ovoviviparous salamanders. The mouths of ovoviviparous embryos open when digits are differentiating in the forelimbs $\left(\mathrm{d}\right.$ and $\left.\mathrm{d}^{\prime}\right)$; at this developmental stage, however, ovoviviparous embryos are still within the egg membranes. Hatching and the switch from the lecithotrophic phase to active feeding in ovoviviparous embryos occur when they are delivered in water as larvae and they start the aquatic free-living phase.

The embryos have some muscular activity. Melanophores are scattered along the dorsal line. The pharyngeal region and the anterior part of the digestive tract (D) are differentiated. Ovoviviparous embryos at the same stage (incipient forelimbs) differ morphologically (Fig. 1f). The cephalic and caudal regions are well elevated from the yolk mass, which is centered in the ventral area, where the digestive tract will develop. Furthermore, viviparous embryos hatch precociously at this developmental stage. In contrast, ovoviviparous embryos hatch only after 80 
90 days of development, just prior or during their release into water.

(4) Developmental rates of the viviparous embryos are heterogeneous (Fig. 1g), whereas ovoviviparous embryos develop in synchrony (Fig. 1h). This pattern is consistently found in all the ovoviviparous and viviparous females studied.

(5) Fore- and hindlimbs of viviparous and ovoviviparous have the same degree of differentiation (Fig. 2, a and b, $\mathrm{a}^{\prime}$ and $\left.b^{\prime}\right)$, but they differ dramatically in other respects. The mouths of the viviparous embryos (Fig. 2, a and $\mathrm{a}^{\prime}$ ) open and the balancers are resorbed earlier in viviparous than in ovoviviparous embryos (Fig. 2, b and b'). Furthermore, the yolk mass of the viviparous embryos is drastically reduced and the anterior part of the digestive tract $(\mathrm{D})$ is developed. Viviparous embryos attain this stage after 12 or 13 days, whereas the ovoviviparous embryos require approximately 19 days.

Viviparous embryos start to feed actively within the maternal oviducts. Although neither their mouths nor their limbs are fully developed, the embryos are capable of predation on arrested eggs (oophagy) and other embryos (adelphophagy; Figs. 2c and 3). The extra yolk fills the precociously differentiated portion of the digestive tract. As a result of the intrauterine cannibalism, viviparous embryos quickly attain their larval morphology, while retaining a large amount of yolk in their digestive tracts. The supplementary nutrients enable the viviparous individuals to reach metamorphosis, then birth, after 90 days of intrauterine development. In contrast, ovoviviparous embryos consume their yolk masses as they develop with no extra nutrients obtained through the ingestion of eggs or siblings (Fig. 1d). At about the time yolk is exhausted and larval form is achieved, hatching, birth, or both take place in the time span in which viviparous forms have reached terrestriality. Larvae are aquatic for one to several months before they metamorphose and become terrestrial. Viviparous juveniles are, on average, smaller than the ovoviviparous ones, although the size of the former falls within the range of variability found in ovoviviparous populations (Rivera et al. 1999; D. Buckley personal observation). Supplementary nutrients are available to viviparous embryos because the embryos develop more rapidly, but these nutrients do not cause an increase in size of the metamorphosed juveniles (Kopp and Baur 2000; Alcobendas et al. 2004).

\section{HETEROCHRONIC PATTERNS IN VIVIPAROUS S. SALAMANDRA}

Heterochronic modifications of ontogenetic trajectories have been associated with the evolution of life-history traits in

Fig. 3. Intrauterine cannibalism in viviparous S. salamandra embryos. The precocious hatching and opening of the mouth, together with the early differentiation of the digestive tract, permit the feeding of the embryos within the maternal genital tract. Viviparous embryos feed on abortive eggs (oophagy [a, b]), or on other siblings (adelphophagy [c, d]). The intrauterine cannibalistic behavior never occurs in ovoviviparous embryos. a: Viviparous embryo feeding on an abortive egg. Although neither the mouth nor the dentition are completely developed, embryos are able to ingest the big and yolky eggs $(3-3.5 \mathrm{~mm}$ in diameter). The ingested yolk fills the anterior part of the digestive tract, which differentiates preco-
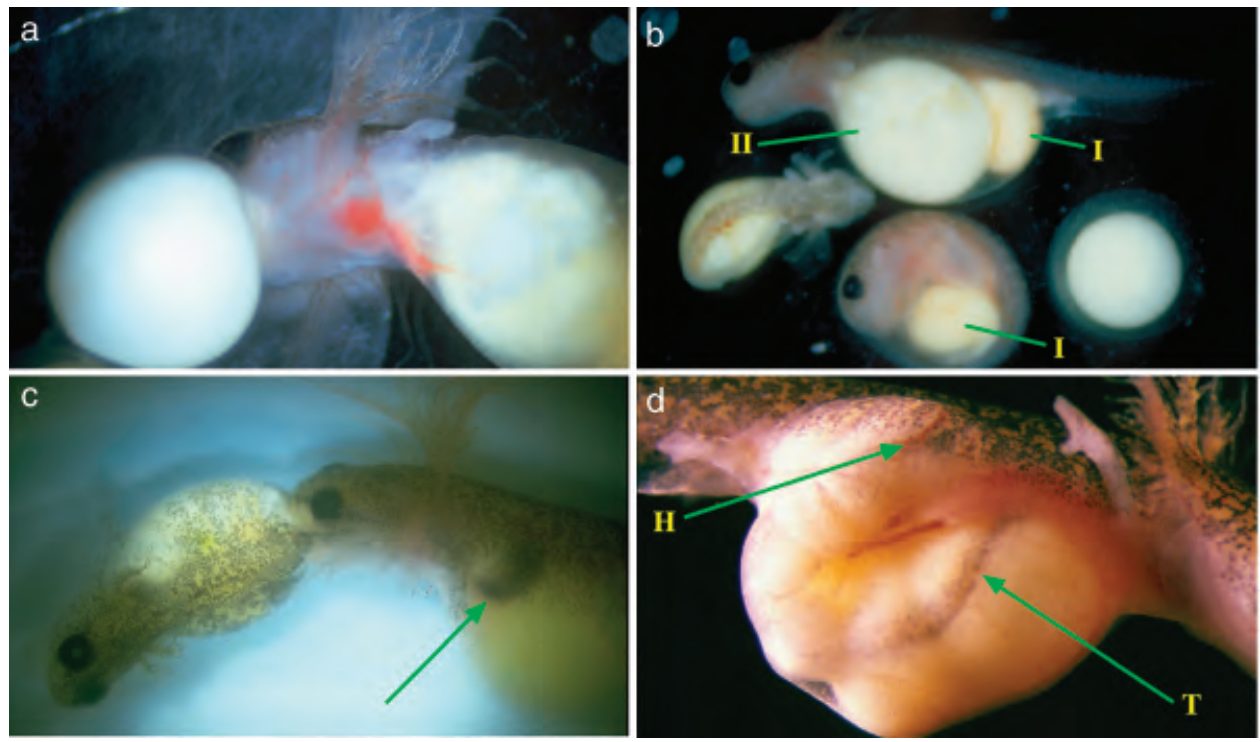
ciously in viviparous embryos. b:

Sibs from the same maternal oviduct. Viviparous embryos are found at different developmental stages within the maternal genital tract. We observe one nonhatched and one hatched embryo in similar developmental stages, together with an abortive egg and one embryo in an earlier development stage. The hatched embryo has two yolk masses within its digestive tract. The first one (I) contains the yolk remaining from the original provision of the egg. The second one (II) corresponds to the ingested yolk that comes from cannibalizing abortive eggs. Within the digestive tract of the nonhatched embryo, we find only the remains of the original egg provision (I). The nonhatching of viviparous embryos within the oviducts is an uncommon situation. Normally, embryos hatch precociously during development. c: Adelphophagy in viviparous embryos. The arrow points to the tail tip of the cannibalized embryo, which is filling the anterior part of the digestive tract. (d): This embryo presents a large and irregular yolk mass within its digestive tract due, again, to the intrauterine ingestion of abortive eggs and one sib. Arrows point to the head $(\mathrm{H})$ and the tail $(\mathrm{T})$ of the cannibalized sib. 
amphibians (Emerson 1986; Hanken 1992, 1999; Ryan and Semlitsch 1998; Denoël et al. 2005). We report an example in which heterochronic shifts seem to result in the evolution of a new reproductive strategy, viviparity, in the otherwise ovoviviparous fire salamander, $S$. salamandra. The three main heterochronic patterns encountered are described below (Fig. 4), following definitions in Gould (1977), Alberch et al. (1979), and McKinney and McNamara (1991).

First, the developmental program of viviparous salamanders is accelerated relative to that of ovoviviparous conspecifics. Development of viviparous salamanders through metamorphosis takes 90 days; in the same amount of time, ovoviviparous larvae hatch and are born into water, with metamorphosis occurring often months later. The acceleration is possible in part because more food is available owing to intrauterine cannibalistic feeding (oophagy and adelphophagy). However, the acceleration also occurs during the prehatching, nonfeeding lecithotrophic stages of development. Thus, the increased developmental rate in part must be determined intrinsically.

Second, pre-displacement and accelerated development characterizes cephalic and pharyngeal structures. These structures, especially those involved in feeding, such as the mouth and the digestive tract (e.g., stomodeum opening, development of the jaw system and of the stomach), develop earlier in viviparous than in ovoviviparous embryos and the sequence of developmental events in the two strategies is not parallel. Two heterochronic patterns (pre-displacement and acceleration) permit precocious feeding by viviparous embryos. It is noteworthy that the process of tooth development does not follow the same heterochronic scheme (data not included)

Third, hatching is pre-displaced in viviparous embryos (Figs. 1 and 3). It is not known how hatching is mediated in $S$. salamandra; therefore, we cannot determine exactly what process is pre-displaced in the viviparous ontogenetic sequence.

Dopazo and Alberch (1994) hypothesized that the presence of unfertilized or abortive eggs, a "physiological malfunction," underlies the evolution of viviparity in S. salamandra. The extra nutrients available would have triggered the selection of embryos that grow faster and are capable of feeding on the available eggs or other siblings. The acceleration of the rate of morphological change or the pre-displacement of the onset of metamorphosis would explain the heterochronic patterns observed. Dopazo and Korenblum (2000) formalized this evolutionary scenario; the number of eggs produced and fertilized per female is a trait under strong selection. However, the co-option of eggs for nutrition creates a new intrauterine environment in which selection would favor the acceleration of developmental rates and cannibalism. The exaptive scenario eventually would lead to the evolution of viviparity in the species.

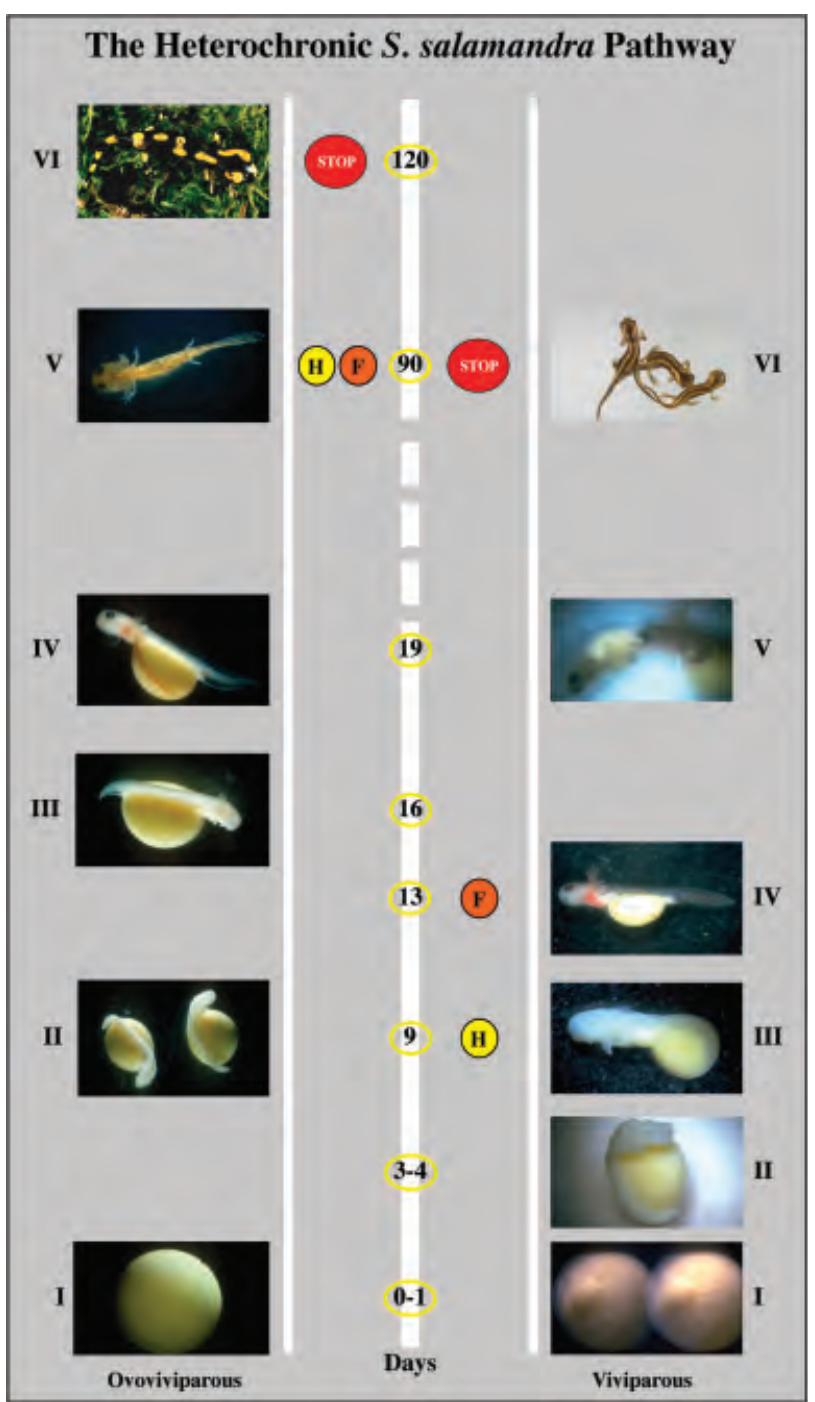

Fig. 4. The "Heterochronic S. salamandra Pathway." As a schematic summary, the heterochronic patterns revealed during the ontogeny of ovoviviparous and viviparous embryos are shown on a temporal axis. The axis starts at Stage I/Day 0 (Gastrulation); key developmental events are represented on two parallel pathways for comparison. Developmental stages have been created for this study, based on the development of the limbs. Roman numerals, comparable developmental stages; h, hatching; f, end of the lecithotrophic phase, start of active feeding; STOP, metamorphosis. The key features that characterize the development of the viviparous embryos involve the presence of abortive and unfertilized eggs (I), the acceleration of the developmental sequences, perceptible from the early stages of development (e.g., stage II), the predisplacement of hatching $(\mathrm{H}$, stage III), and the pre-displacement of structures related to feeding ( $\mathrm{F}$, stage IV). As a result, the developmental phase from fertilization to metamorphosis in viviparous embryos is drastically shortened compared to that in ovoviviparous individuals. The former metamorphose and are delivered as terrestrial juveniles after 90 days of intrauterine development (VI). Ovoviviparous individuals start their aquatic larval stage after 90 days (V), hatching and active feeding occurring at this point. They will stay in water from one to several months before completing metamorphosis (VI). 
The results obtained in our study support some of the Dopazo and Alberch (1994) hypotheses. We have shown that developmental rates are accelerated and that hatching is predisplaced in viviparous embryos. The onset of metamorphosis, though, is not pre-displaced. Furthermore, we have demonstrated that the structures related to feeding develop earlier in viviparous embryos. However, our data do not help us to ascertain whether the co-option of unfertilized and abortive eggs triggered the evolution of viviparity or whether, instead, other developmental processes were responsible. One of the main problems in postulating evolutionary scenarios is that they are ad hoc hypotheses that cannot be falsified (Wake 1992); therefore, they are not useful frameworks for further analyses. Instead, we think that the study of the evolution of viviparity in $S$. salamandra requires integration of new approaches and techniques at different levels of biological organization.

\section{AN INTEGRATIVE APPROACH TO THE STUDY OF THE EVOLUTION OF VIVIPARITY IN S. SALAMANDRA}

We have identified the developmental clues that differentiate the ontogenies of ovoviviparous and viviparous salamander embryos at the morphological level. This work, together with the previous phylogenetic and phylogeographic studies (García-París et al. 2003), constitutes an essential step towards a comprehensive mechanistic approach to the analysis of the evolution of viviparity in S. salamandra (Autumn et al. 2002). The next step involves isolating the specific elements, and the cellular, genetic, and epigenetic developmental mechanisms responsible for the observed pattern (Smith 2003). In this context, we recently have undertaken the description of the heterochronic patterns at different levels of hierarchical complexity (external morphology, tissue, cellular, or genetic). This approach will provide us with a robust framework within which to analyze the developmental mechanisms that underlie the ontogenetic modifications observed (Raff and Wray 1989).

The integrated framework also will permit us to explore the importance of the ontogenetic modifications in the evolution of viviparous adult salamander morphology and life-history traits. Little is known about derivatives of the embryonic structures in urodeles (Hanken 1999; Gross and Hanken 2005). A detailed analysis of the embryological origins of larval and adult structures will help us understand the developmental mechanisms that drive the evolution of larval morphology and the relation between larval and adult structures. We also will be able to determine the extent to which larval structures may limit or constrain the evolution of adult morphology (Wake and Roth 1989; Wake 1991). The highly specialized larval structure may limit the range of possible adult structures. Larval constraints on adult structures have been relaxed in several different ways-e.g., (1) the cellular lines that give rise to larval and adult structures are compartmentalized early in the embryo (e.g., Alberch 1987, 1989); (2) larval structures are co-opted for new adult functions (e.g., Alberch 1987; Hanken 1999); and (3) in the extreme, the free-living larval stage is eliminated in direct developers. The possible new developmental combinations that arise in direct developers under this "ontogenetic repatterning" (Roth and Wake 1985; Wake and Roth 1989) are fundamental to the morphological diversification of plethodontid salamanders, for example (Wake and Roth 1989; Wake 1991; Hanken 1999). Interestingly, $S$. salamandra, as do most viviparous amphibians, retains the larval developmental program, even though the larvae develop within the maternal oviducts. The presence of larval structures specialized for a free-living aquatic stage is thought to have facilitated the evolution of the derived reproductive mode by co-opting larval structures for new functions (Hanken 1999; Wake 2004). We are conducting a detailed survey of the cellular origins of the larval and adult structures in viviparous and ovoviviparous fire salamanders. We anticipate that this study will elucidate the relative importance of ontogenetic modifications related to viviparity to the evolution of adult traits such as coloration patterns (striped viviparous vs. spotted ovoviviparous adults), size (smaller viviparous vs. larger ovoviviparous adults), and other morphological characteristics (e.g., rounded snouts in viviparous vs. pointed snouts in ovoviviparous adults).

Viviparity is an uncommon phenomenon in Caudata. It has evolved independently in only a few species of salamanders, all within Salamandridae (Wake 1993; Greven 1998; Veith et al. 1998). Sixteen genera and 66 species are recognized in the family (e.g., Weisrock et al. 2006). Viviparity occurs in the seven species within Lyciasalamandra, in S. atra, in S. lanzai, and in S. salamandra (Greven 1977, 1998; Özeti 1979; Nascetti et al. 1988; Veith et al. 1998). Also, it has been suggested that viviparity occurs in S. algira, although little is known about the physiological characteristics of live-bearing in this species (Martínez et al. 1997; Donaire Barroso 2001). Therefore, viviparity has evolved independently at least four times in 11 species, if we consider the seven Lyciasalamandra taxa formerly referred to subspecies of the genus Mertensiella to be valid species (Veith and Steinfartz 2004). The physiology of viviparity differs in salamandrids. For instance, gestation in $S$. atra is extended up to 3 or 4 years. Females produce two juveniles. Only one egg is fertilized in each oviduct and the unfertilized eggs serve as nutrients for the developing embryos. Furthermore, the mothers also supply the embryos with a nutritious material secreted in the uterus (e.g., Wake 1993; Greven and Guex 1994; Greven 1998). The integrated framework used in this work must be extended to the other species within the family. The developmental and phylogenetic approaches will enable us to differentiate between homologous 
and homoplastic patterns and processes among viviparous salamandrids, and to speculate about the association of these patterns and processes with the diversity of reproductive modes in Salamandridae. Homoplasies, especially parallelisms, may be informative about design limitations and developmental constraints (Wake 1991; Hodin 2000). Furthermore, the homoplastic coevolution of a set of characters may indicate that this set actually is behaving as a module or unit of evolution (e.g., Galis et al. 2003; Schlosser 2004). Therefore, the study of homoplastic patterns can inform us about the developmental processes underlying morphological evolution (Wake 1991). Eventually, the developmental and phylogenetic approaches should be extended to the rest of the urodele families, which have adopted different developmental "solutions" such as direct development or paedomorphosis. This will permit us to sort out how the different reproductive modes and life-history traits have evolved in urodeles.

\section{CONCLUSION: S. SALAMANDRA AS A PARADIGMATIC “NONMODEL” ORGANISM}

A fundamental problem in evolutionary theory concerns the relationship between microevolutionary processes, amenable to empirical testing, and the origin of key innovations at the macroevolutionary level. In the case presented here, evolutionary novelties that originate from heterochronic changes during embryonic development lead to viviparity, thereby facilitating access to resources both in the oviduct and in an otherwise nonaccessible terrestrial ecological niche. Therefore, viviparity is a trait that fulfills the criteria to be considered a relevant feature of macroevolution. Moreover, the origin of viviparity as a local, intraspecific variant allows us to study the phenomenon from a strictly microevolutionary perspective; thus, viviparity is an unlikely and unique empirical system for the examination of the origin of key innovations. In previous phylogenetic and phylogeographic studies (GarcíaParís et al. 2003), we identified distinct contact zones where viviparous and ovoviviparous $S$. salamandra meet and mate. These "reproductive hybrid zones" constitute unusual natural laboratories in which to study the dynamics of the evolution of the novelty in action. Thus, there is a 2-fold interest in $S$. salamandra as a model organism in evolutionary biology. First, $S$. salamandra facilitates empirical analysis of the way in which evolutionary novelties arise through the modification of developmental programs (Hanken 1999; Wake 2003). Second, because variation in reproductive modes and the associated variation in sequences of development occur in neighboring conspecific populations, S. salamandra represents a unique biological model suitable to endow the evo-devo research program with a populational perspective (Baguña and García-Fernández 2003). We present this research program in genetics, development, and evolutionary biology as case study for an integrative approach to the study of macroevolutionary processes.

\section{Acknowledgments}

This research was possible owing to the energy, enthusiasm, ideas, and wisdom of Prof. P. Alberch who died during the course of this research. B. Sanchiz, M. J. Blanco, B. Arconada, G. Parra-Olea, and D. B. Wake have contributed to the improvement of the manuscript. We also greatly appreciate the helpful comments and suggestions made by Rudolf A. Raff, Linda Trueb and an anonymous reviewer. We acknowledge the Agencias de Medio Ambiente de Castilla-León and the Principado de Asturias of Spain, which provided us the necessary collecting permits. D. B. is currently supported by a postdoctoral fellowship (Ex2004-0724) of the Ministerio de Educación y Ciencia of Spain (MEC). M. H. W. thanks the U.S. National Science Foundation for research support, currently through IBN 0212027.

\section{REFERENCES}

Alberch, P. 1995. "Ontogeny and Phylogeny" revisited: 18 years later of heterochrony and developmental constraints. In R. Arai, M. Kato, and Y. Doi (eds.). Biodiversity and Evolution. The National Science Museum Foundation, Tokyo, pp. 229-249.

Alberch, P. 1989. Development and the evolution of amphibian metamorphosis. In H. Splechtna and H. Hilgers (eds.). Trends in Vertebrate Morphology, Progress in Zoology. Vol. 35. Gustav Fischer Verlag, Stuttgart, pp. 163-173.

Alberch, P. 1987. Evolution of a developmental process: irreversibility and redundancy in amphibian metamorphosis. In R. A. Raff and E. Raff (eds.). Development as an Evolutionary Process, Marine Biological Laboratories (Woods Hole, MA) Lectures in Biology Series. Vol. 8. Alan R. Liss Inc, New York, pp. 23-46.

Alberch, P., and Blanco, M. J. 1996. Evolutionary patterns in ontogenetic transformation: from laws to regularities. Int. J. Dev. Biol. 40: 845-858.

Alberch, P., Gould, S. J., Oster, G. F., and Wake, D. B. 1979. Size and shape in ontogeny and phylogeny. Paleobiology 5: 296-317.

Alcobendas, M., Buckley, D., and Tejedo, M. 2004. Variability in survival, growth, and metamorphosis in the larval fire salamanders (Salamandra salamandra): effects of larval birth size, sibships and environment. Herpetologica 60: 232-245.

Alcobendas, M., Dopazo, H., and Alberch, P. 1996. Geographic variation in allozymes of populations of Salamandra salamandra (Amphibia: Urodela) exhibiting distinct reproductive models. J. Evol. Biol. 9: 83-102.

Andrews, R. M. 1997. Evolution of viviparity: variation between two sceloporine lizards in the ability to extend egg retention. J. Zool. London 243: 579-595.

Armstrong, J. B., Duhon, S. T., and Malacinski, G. M. 1989. Raising the axolotl in captivity. In J. B. Armstrong and G. M. Malacinski (eds.). Developmental Biology of the Axolotl. Oxford University Press, New York, pp. 220-227.

Autumn, K., Ryan, M. J., and Wake, D. B. 2002. Integrating historical and mechanistic biology enhances the study of adaptation. Quart. Rev. Biol. 77: $383-408$

Baguñá, J., and García-Fernández, J. 2003. Evo-Devo: the long and winding road. Int. J. Dev. Biol. 47: 705-713.

Beck, C. 1998. Mode of fertilization and parental care in anurans. Anim. Behav. 55: 439-449.

Blackburn, D. G. 1994. Discrepant usage of the term "ovoviviparity" in the herpetological literature. Herpet. J. 4: 65-72.

Blanco, M. J., and Alberch, P. 1992. Caenogenesis, developmental variability, and evolution in the carpus and the tarsus of the marbled newt Triturus marmoratus. Evolution 46: 677-687.

Bonett, R. M., and Chippindale, P. T. 2006. Streambed microstructure predicts evolution of development and life history mode in the plethodontid salamander Eurycea tynerensis. BMC Biol. 4: 6. 
Bruce, R. C. 2003. Life histories. In D. M. Sever (ed.). Reproductive Biology and Phylogeny. Vol. 1, Reproductive Biology and Phylogeny of Urodela. Science Publisher Inc, Enfield, pp. 477-526.

Buckley, D., Alcobendas, M., García Paris, M., and Wake, M. M. 2007. "Development of the fire Salamander (Salamander Salamander) from gastrulation to metamorphosis: A staging table" in preparation.

Denoël, M., and Joly, P. 2000. Neoteny and progenesis as two heterochronic processes involved in paedomorphosis in Triturus alpestris (Amphibia: Caudata). Proc. R. Soc. London. B 267: 1481-1485.

Denoël, M., Joly, P., and Whiteman, H. H. 2005. Evolutionary ecology of facultative paedomorphosis in newts and salamanders. Biol. Rev. 80: 663-671.

Donaire Barroso, D. 2001. Confirmación de desarrollo larvario completo intrauterino en Salamandra algira (Bedriaga, 1883) el noroeste de Marruecos. Bull. Soc. Cat. Herpet. 15: 107-110.

Dopazo, H., and Alberch, P. 1994. Preliminary results on optional viviparity and intrauterine siblicide in Salamandra salamandra populations from northern Spain. Mertensiella 4: 125-138.

Dopazo, H. J., and Korenblum, M. 2000. Viviparity in Salamandra salamandra (Amphibia: Salamandridae): adaptation or exaptation? Herpetologica 56: 144-152.

Duellman, W. E. 2003. An overview of anuran phylogeny, classification, and reproduction. In B. G. M. Jamieson (ed.). Reproductive Biology and Phylogeny. Vol. 1, Reproductive Biology and Phylogeny of Anura. Science Publisher Inc, Enfield, pp. 1-18.

Duellman, W. E., and Trueb, L. 1986. Biology of Amphibians. McGrawHill, New York.

Emerson, S. B. 1986. Heterochrony and frogs: the relationship of a life history trait to morphological form. Am. Nat. 127: 167-183.

Fink, W. L. 1982. The conceptual relationship between ontogeny and phylogeny. Paleobiology 8: 254-264.

Galis, F., Wagner, G., and Jockusch, E. 2003. Why is limb regeneration possible in amphibians but not in reptiles, birds, and mammals? Evol. Dev. 5: 208-220.

García-París, M., Alcobendas, M., Buckley, D., and Wake, D. B. 2003. Dispersal across contact zones in Iberian populations of fire salamanders (Salamanda salamandra) inferred from discordance of genetic and morphological traits. Evolution 57: 129-143.

Gould, S. J. 1977. Ontogeny and Phylogeny. Harvard University Press, Cambridge, MA.

Greven, H. 2003. Larviparity and pueriparity. In D. M. Sever (ed.). Reproductive Biology and Phylogeny Vol. 1, Reproductive Biology and Phylogeny of Urodela. Science Publisher Inc, Enfield, pp. 447-475.

Greven, H. 1998. Survey of the oviduct of salamandrids with special reference to the viviparous species. J. Exp. Zool. 282: 507-525.

Greven, H. 1977. Comparative ultraestructure investigations of the uterine epithelium in the viviparous Salamandra atra Laur., the ovoviviparous Salamandra salamandra (L.) (Amphibia, Urodela). Cell Tiss. Res. 181: 215-237.

Greven, H., and Guex, G. D. 1994. Structural and physiological aspects of viviparity in Salamandra salamandra. Mertensiella 4: 139-160.

Gross, J. B., and Hanken, J. 2005. Cranial neural crest contributes to the bony skull vault in adult Xenopus laevis: insights from cell labeling studies. J. Exp. Biol. 304B: 169-176.

Haddad, C. F. B., and Prado, C. P. A. 2005. Reproduction modes in frogs and their unexpected diversity in the Atlantic forest of Brazil. BioScience 55: $207-217$.

Hanken, J. 1999. Larvae in amphibian development and evolution. In B. K. Hall and M. H. Wake (eds.). The Origin and Evolution of Larval Forms. Academic Press, San Diego, pp. 61-108.

Hanken, J. 1992. Life history and morphological evolution. J. Evol. Biol. 5: 549-557.

Heulin, B., Osenegg-Leconte, K., and Michel, D. 1997. Demography of a bimodal reproductive species of lizard (Lacerta vivipara): survival and density characteristics of oviparous species. Herpetologica 53: 432-444.

Hodin, J. 2000. Plasticity and constraints in development and evolution. J. Exp. Zool. 288: 1-20.

Joly, J. 1986. La reproduction de la salamandre terrestre (Salamandra salamandra L.). In P. P. Grasse and M. Delsol (eds.). Traité de Zoologie. Vol. 14, Amphibiens. Masson, Paris, pp. 471-486.
Joly, J., Chesnel, F., and Boujard, D. 1994. Biological adaptations and reproductive strategies in the genus Salamandra. Mertensiella 4: 255-269.

Kopp, M., and Baur, B. 2000. Intra- and inter-litter variation in life-history traits in a population of fire salamanders (Salamandra salamandra terrestris). J. Zool. Lond. 250: 231-236.

Lehtinen, R. M., and Nussbaum, R. A. 2003. Parental care: a phylogenetic perspective. In B. G. M. Jamieson (ed.). Reproductive Biology and Phylogeny. Vol. 2, Reproductive Biology and Phylogeny of Anura. Science Publisher Inc, Enfield, pp. 343-386.

Martínez, F. J., Ruiz, J. L., and Mohamed, L. 1997. Una nueva especies para la herpetofauna de Ceuta: Salamandra salamandra algira. Bol. Asoc. Herpet. Esp. 8: 6-8.

McKinney, M. L., and McNamara, K. J. 1991. Heterochrony. The Evolution of Ontogeny. Plenum Press, New York.

McNamara, K. J., and McKinney, M. L. 2005. Heterochrony, disparity, and macroevolution. Paleobiology 31: 17-26.

Mink, D. G., and Sites Jr., J. W. 1996. Species limits, phylogenetic relationships, and origins of viviparity in the scalaris complex of the lizard genus Sceloporus (Phrynosomatidae: Sauria). Herpetologica 52: 551-571.

Nascetti, G., Andreone, F., Capula, M., and Bullini, L. 1988. A new Salamandra species from South-Western Alps. Boll. Mus. Reg. Sci. Nat. Torino 6: 617-638.

Nussbaum, R. A. 2003. Parental care. In D. M. Sever (ed.). Reproductive Biology and Phylogeny. Vol. 1, Reproductive Biology and Phylogeny of Urodela. Science Publisher Inc, Enfield, pp. 527-612.

Özeti, N. 1979. Reproductive biology of the salamander Mertensiella luschani antalyana. Herpetologica 35: 193-197.

Parichy, D. M. 2001. Pigment patterns of ectothermic vertebrates: heterochronic vs. nonheterochronic models for pigment pattern evolution. In M. L. Zelditch (ed.). Beyond Heterochrony: The Evolution of Development. Wiley-Liss Inc, New York, pp. 229-269.

Poe, S., and Wake, M. H. 2004. Quantitative tests of general models for the evolution of development. Am. Nat. 164: 415-422.

Qualls, F. J., and Shine, R. 1998. Geographic variation in lizards phenotypes: importance of the incubation environment. Biol. J. Linn. Soc. 64 477-491.

Raff, R. A., and Wray, G. A. 1989. Heterochrony: developmental mechanisms and evolutionary results. J. Evol. Biol. 2: 409-434.

Rivera, X., Simón, J. G., and Melero, J. A. 1999. Observaciones en el ciclo larvario de Salamanda salamandra (Linnaeus, 1758) en un población de Cataluña (Nordeste de la Península Ibérica). Bull. Soc. Catal. Herpet. 14: 62-69.

Roth, G., and Wake, D. B. 1985. Trends in the functional morphology and sensorimotor control of feeding behavior in salamanders: an example of the role of internal dynamics in evolution. Acta Biotheoretica 34: 175-192.

Ryan, T. J., and Semlitsch, R. D. 2003. Growth and the expression of alternative life cycles in the salamander Ambystoma talpoideum (Caudata: Ambystomatidae). Biol. J. Linn. Soc. 80: 639-646.

Ryan, T. J., and Semlitsch, R. D. 1998. Intraspecific heterochrony and life history evolution: decoupling somatic and sexual development in a facultatively paedomorphic salamander. Proc. Natl. Acad. Sci. U.S.A. 95: 5643-5648

Safi, R., et al. 2006. Pedomorphosis revisited: thyroid hormone receptors are functional in Necturus maculosus. Evol. Dev. 8: 284-292.

Salvador, A., and García-París, M. 2001. Anfibios Españoles. Identificación, Historia Natural y Distribución. Canseco Editores, S. L., Talavera de la Reina.

Schlosser, G. 2004. Amphibian variations: the role of modules in mosaic evolution. In B. K. Hall, R. D. Pearson, and G. B. Muller (eds.) Environment, Development, and Evolution: Towards a Synthesis The Vienna Series in Theoretical Biology. Vol. 4. MIT Press, Cambridge, MA, pp. 143-179.

Sessions, S. K., MacGregor, H. C., Schmid, M., and Haaf, T. 1988. Cytology, embryology, and evolution of the developmental arrest syndrome in newts of the genus Triturus (Caudata: Salamandridae). J. Exp. Zool. 248: $321-334$.

Shine, R. 1985. The evolution of viviparity in reptiles: an ecological analysis. In C. Gans and F. Billet (eds.). Biology of the Reptilia. Vol. 15. Development. Wiley, New York, pp. 605-694. 


\section{Buckley et al.}

Smith, K. K. 2003. Time's arrow: heterochrony and the evolution of development. Int. J. Dev. Biol. 47: 613-621.

Smith, K. K. 2002. Sequence heterochrony and the evolution of development. J. Morph. 252: 82-97.

Smith, S. A., and Shine, R. 1997. Intraspecific variation in reproductive mode within the Scindid lizard Saiphos equalis. Austr. J. Zool. 45: 435-445.

Summers, K., McKeon, C. S., and Heying, H. 2006. The evolution of parental care and egg size: a comparative analysis in frogs. Proc. R. Soc. Lond. B 273: 687-692.

Thiesmeier, B., and Haker, K. 1990. Salamandra salamandra bernardezi Wolterstorff 1928 aus Oviedo, Spanien, nebst Bemerkungen zur Viviparie in der Gattung Salamandra. Salamandra 26: 140-154.

Veith, M., and Steinfartz, S. 2004. When non-monophyly results in taxonomic consequences-the case of Mertensiella within the Salamandridae (Amphibia: Urodela). Salamandra 40: 67-80

Veith, M., Steinfartz, S., Zardoya, R., Seitz, A., and Meyer, A. 1998. A molecular phylogeny of 'true' salamanders (family Salamandridae) and the evolution of terrestriality of reproductive modes. J. Zool. Syst. Evol. Res. 36: 7-16.

Wake, D. B. 1991. Homoplasy: the result of natural selection, or evidence of design limitations? Am. Nat. 138: 543-567.

Wake, D. B., and Roth, G. 1989. The linkage between ontogeny and phylogeny in the evolution of complex systems. In D. B. Wake and G. Roth (eds.). Complex Organismal Functions: Integration and Evolution in Vertebrates. John Wiley \& Sons Ltd, New York, pp. 361-377.

Wake, M. H. 2004. Environmental effects, embryonization, and the evolution of viviparity. In B. K. Hall, R. D. Pearson, and G. B. Muller (eds.). Environment, Development, and Evolution: Towards a Synthesis. The Vienna series in Theoretical Biology. Vol. 4. MIT Press, Cambridge, MA, pp. 151-170.

Wake, M. H. 2003. Reproductives modes, ontogenies, and the evolution of body forms. Ann. Biol. 53: 209-223.

Wake, M. H. 2002. Viviparity and oviparity. In M. D. Pagel (ed.). Encyclopedia of Evolution. Vol. 2. Oxford University Press, New York, pp. 1141-1143.

Wake, M. H. 1993. Evolution of oviductal gestation in Amphibians. J. Exp. Zool. 266: 394-413.

Wake, M. H. 1992. Evolutionary scenarios, homology and convergence of structural specializations for vertebrate viviparity. Am. Zool. 32: 256-263.

Wake, M. H. 1989. Phylogenesis of direct development and viviparity in vertebrates. In D. B. Wake and G. Roth (eds.). Complex Organismal Functions: Integration and Evolution in Vertebrates. John Wiley \& Sons Ltd, New York, pp. 235-250.

Wake, M. H. 1982. Diversity within a framework of constraints: reproductives modes in amphibians. In D. Mossalowski and G. Roth (eds.) Environmental Adaptation and Evolution, a Theoretical and Empirical Approach. Gustav Fisher, Stuttgart, pp. 87-106.

Weisrock, D. W., et al. 2006. A molecular assessment of phylogenetic relationships and lineage accumulation rates within the family Salamandridae (Amphibia, Caudata). Mol. Phyl. Evol. 41: 368-383.

Whiteman, H. H. 1994. Evolution of facultative paedomorphosis in salamanders. Quart. Rev. Biol. 69: 205-221.

Wiens, J. J., Bonett, R. M., and Chippindale, P. T. 2005. Ontogeny discombulates phylogeny: paedomorphosis and higher-level salamander relationships. Syst. Biol. 564: 91-105.

Wourms, J. P. 1981. Viviparity: the maternal-fetal relationship in fishes. Am. Zool. 21: 473-515.

Zelditch, M. L. (ed.). 2001. Beyond Heterochrony. The Evolution of Development. Wiley-Liss Inc, New York. 